\title{
RGK regulation of voltage-gated calcium channels
}

\author{
BURAEI Zafir ${ }^{1 *}$, LUMEN Ellie $^{1}$, KAUR Sukhjinder ${ }^{1} \&$ YANG Jian ${ }^{2,3^{*}}$ \\ ${ }^{1}$ Department of Biology, Pace University, New York, NY 10038, USA; \\ ${ }^{2}$ Ion Channel Research and Drug Development Center, and Key Laboratory of Animal Models and Human Disease Mechanisms of the \\ Chinese Academy of Sciences and Yunnan Province, Kunming Institute of Zoology, Chinese Academy of Sciences, Kunming 650223, China; \\ ${ }^{3}$ Department of Biological Sciences, Columbia University, New York, NY 10027, USA
}

Received August 15, 2014; accepted September 2, 2014

\begin{abstract}
Voltage-gated calcium channels (VGCCs) play critical roles in cardiac and skeletal muscle contractions, hormone and neurotransmitter release, as well as slower processes such as cell proliferation, differentiation, migration and death. Mutations in VGCCs lead to numerous cardiac, muscle and neurological disease, and their physiological function is tightly regulated by kinases, phosphatases, G-proteins, calmodulin and many other proteins. Fifteen years ago, RGK proteins were discovered as the most potent endogenous regulators of VGCCs. They are a family of monomeric GTPases (Rad, Rem, Rem2, and Gem/Kir), in the superfamily of Ras GTPases, and they have two known functions: regulation of cytoskeletal dynamics including dendritic arborization and inhibition of VGCCs. Here we review the mechanisms and molecular determinants of RGK-mediated VGCC inhibition, the physiological impact of this inhibition, and recent evidence linking the two known RGK functions.
\end{abstract}

calcium, channel modulation, trafficking, cardiac physiology, neurobiology, beta subunit

Citation: Buraei Z, Lumen E, Kaur S, Yang J. RGK regulation of voltage-gated calcium channels. Sci China Life Sci, 2015, 58: 28-38, doi: $10.1007 / \mathrm{s} 11427-014-4788-\mathrm{x}$

\section{Introduction}

\subsection{Voltage-gated calcium channels}

$\mathrm{Ca}^{2+}$ ions play a critical role in biological processes ranging from neurotransmitter and hormone release to muscle contraction, cell division, differentiation, migration and death. In nerve and muscle cells, the principal entryways for $\mathrm{Ca}^{2+}$ are voltage-gated calcium channels (VGCCs). These are large multisubunit membrane proteins, whose mutations have been implicated in autism, epilepsy, migraine, cardiovascular and skeletal muscle disease, blindness, deafness, pain and other conditions.

The principal component of VGCCs is a large ( 2000-2500 amino acids, 190-250 kD) pore-forming $\alpha_{1}$ subunit or $\mathrm{Ca}_{\mathrm{v}} \alpha_{1} \cdot \mathrm{Ca}_{\mathrm{v}} \alpha_{1}$ has intracellular $\mathrm{N}$ - and C-termini

*Corresponding author (email: zburaei@pace.edu; jianyang@mail.kiz.ac.cn) and four homologous repeats (I-IV), each with six transmembrane segments (S1-S6) and a pore-forming loop. Each S4 segment contains positively charged amino acids and forms the channel's voltage sensor, whose movement upon depolarization leads to channel opening (Figure 1). The voltage sensors' movements elicit minuscule "gating currents" that can be measured independently from the larger $\mathrm{Ca}^{2+}$ currents flowing through the channel's pore. The "gating current" concept is noted here because RGK proteins can restrict the movement of the voltage sensors in some instances [1,2]. The four homologous $\mathrm{Ca}_{\mathrm{v}} \mathrm{\alpha}_{1}$ repeats are connected by three intracellular connecting loops: the I-II loop, II-III loop and III-IV loop. The I-II loop contains the AID ( $\alpha$-interacting domain), which binds to the $\beta$ subunit of VGCCs $\left(\mathrm{Ca}_{v} \beta\right)$. As we discuss later, $\mathrm{Ca}_{v} \beta$ is critical for VGCC function and inhibition by RGKs.

In mammals, distinct $\mathrm{Ca}_{\mathrm{v}} \alpha_{1}$ subunits are encoded by 10 
different genes with over 70 splice variants. $\mathrm{Ca}_{v} \alpha_{1}$ determines and defines the unique biophysical and pharmacological properties of VGCCs (Figure 1). Based on these properties, as well as sequence homology, VGCCs fall into three subfamilies: $\mathrm{Ca}_{\mathrm{v}} 1, \mathrm{Ca}_{\mathrm{v}} 2$ and $\mathrm{Ca}_{\mathrm{v}} 3$, with the subtypes shown in Figure 1. The $\mathrm{Ca}_{\mathrm{v}} 1$ and $\mathrm{Ca}_{\mathrm{v}} 2$ families are more closely related to each other than to $\mathrm{Ca}_{\mathrm{v}} 3$ channels. The latter are low voltage-activated (LVA) and do not have an AID in their I-II loop and do not require any auxiliary subunits for proper expression or function $[3,4]$. In contrast, $\mathrm{Ca}_{\mathrm{v}} 1$ and $\mathrm{Ca}_{\mathrm{v}} 2$ channels (L-, N-, P/Q- and R-type channels)

A
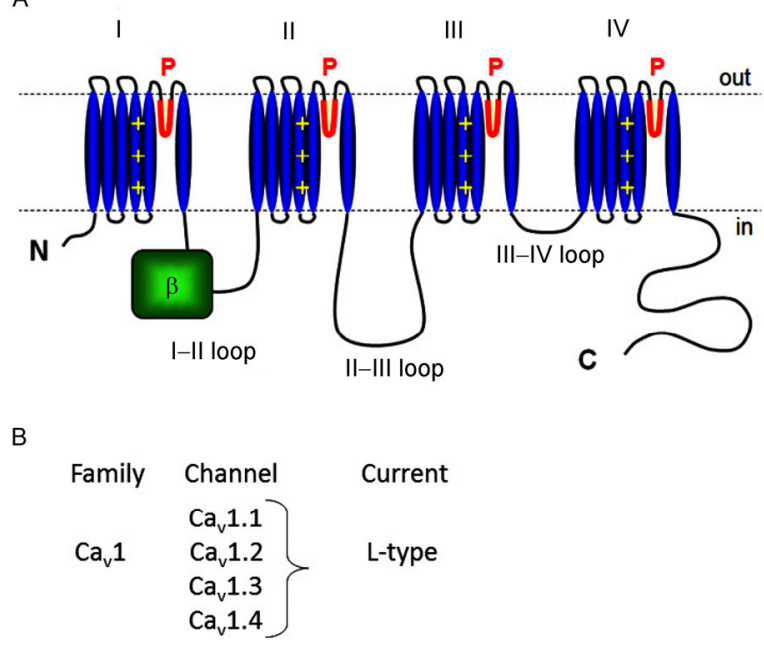

$\begin{array}{lll} & \mathrm{Ca}_{\mathrm{v}} 2.1 & \text { P/Q-type } \\ \mathrm{Ca}_{\mathrm{v}} 2 & \mathrm{Ca}_{\mathrm{v}} 2.2 & \text { N-type } \\ & \mathrm{Ca}_{\mathrm{v}} 2.3 & \text { R-type }\end{array}$

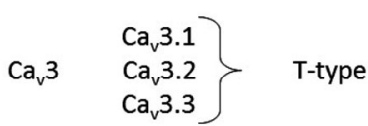

C

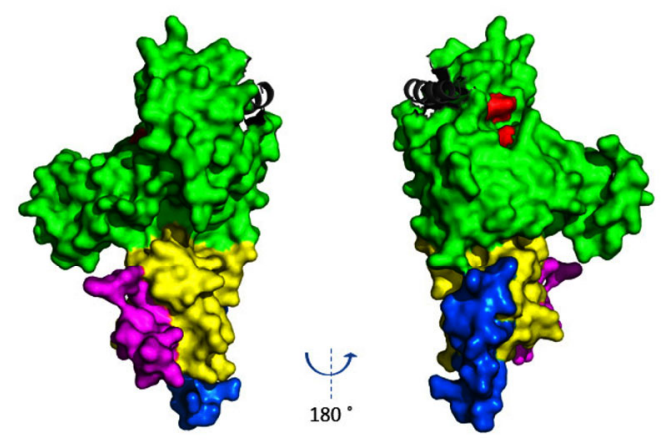

Figure 1 Transmembrane topology of $\mathrm{Ca}_{v} \alpha_{1}$, family classification of VGCCs and the crystal structure of $\mathrm{Ca}_{\mathrm{v}} \beta$. A, The four homologous repeats of $\mathrm{Ca}_{\mathrm{v}} \alpha_{1}$ are indicated by the roman numerals I-IV. Blue segments indicate transmembrane segments S1-S6, with S4 serving as the voltage sensor. The $\beta$ subunit binds to the I-II loop but may also interact with other regions of the channel $[3,4]$. B, Classification of VGCCs. C, The crystal structure of $\mathrm{Ca}_{\mathrm{v}} \beta_{3}$ in complex with the AID (gray helix; PDB: 1VYT). The GK domain is in green, the $\mathrm{SH} 3$ domain in yellow, the HOOK region in magenta and the $\mathrm{N}$-terminus in blue. In red are three aspartic acid residues (D 194, 270 and 272) thought to interact with RGK proteins. generally require higher voltages for activation (HVA channels) and require auxiliary subunits for proper function. In particular, $\mathrm{Ca}_{\mathrm{v}} \beta$ plays a crucial role in trafficking channels to the plasma membrane and fine- tuning channel gating properties $[3,4]$. Not surprisingly, mutations and dysregulation of $\mathrm{Ca}_{\mathrm{v}} \beta$ have been implicated in long QT syndrome, Alzheimer's disease, ataxia, cardiac hypertrophy, seizures, dyskinesia, renal cysts and other disorders $[3,4]$.

There are four different $\mathrm{Ca}_{\mathrm{v}} \beta \mathrm{s}, \mathrm{Ca}_{\mathrm{v}} \beta_{1}-\mathrm{Ca}_{\mathrm{v}} \beta_{4}$, encoded by four genes that give rise to over 20 splice variants. $\mathrm{Ca}_{\mathrm{v}} \beta \mathrm{s}$ are members of the MAGUK (membrane-associated guanylate kinases) family of proteins and have conserved GK and SH3 domains (Figure 1C), which serve as protein-protein interaction modules. In addition, they have a variable HOOK region connecting the GK and SH3 domains, as well as variable $\mathrm{N}$ - and $\mathrm{C}$-termini that functionally distinguish different $\mathrm{Ca}_{\mathrm{v}} \beta \mathrm{s}$.

The conserved $\mathrm{Ca}_{\mathrm{v}} \beta$ GK domain harbors the $\alpha_{1}$-binding pocket (ABP), which binds to the AID and anchors $\mathrm{Ca}_{\mathrm{v}} \beta$ to the channel complex. At a separate site, the GK domain also binds and anchors RGK proteins [5] (Figure 1C). Thus, some mutations can abolish $\mathrm{Ca}_{\mathrm{v}} \beta$-RGK binding while maintaining $\mathrm{Ca}_{\mathrm{v}} \alpha_{1}-\mathrm{Ca}_{\mathrm{v}} \beta$ binding; vice versa, other mutations can abolish $\mathrm{Ca}_{v} \alpha_{1}-\mathrm{Ca}_{v} \beta$ binding while maintaining $\mathrm{Ca}_{\mathrm{v}} \beta$ RGK binding. These and other combinations of mutations have been exploited to dissect the role of $\mathrm{Ca}_{\mathrm{v}} \beta$ in RGK inhibition and uncover direct binding between $\mathrm{Ca}_{\mathrm{v}} \alpha_{1}$ and RGKs $[1,2,5,6]$, as we discuss below.

\subsection{RGK proteins}

All monomeric G-proteins, including RGKs, belong to the Ras superfamily of GTPases. They all have a G-domain composed of five $\mathrm{G}$ regions (G1-G5) involved in guanine nucleotide binding, and two regions that switch their conformation upon GTP/GDP exchange: switch I and switch II. Ras GTPases are further divided into five families, each with distinct functions: Rab, Ran, Ras, Rho, and Arf/Sar1, which are involved, respectively, in vesicular transport, nucleoplasmic transport, gene expression, cytoskeleton rearrangements and vesicle budding [7]. In the early 1990s, the latest family of small GTPases was discovered [8]. These are the RGK GTPases Rad, Rem (also known as Rem1 or Ges), Rem2 and Gem/Kir. Rad was discovered as a Ras-like protein associated with type II diabetes, Gem as a GTP-binding mitogen-induced T-cell protein, and Rem and Rem2 were later identified based on similarity to Rad and Gem. In comparison to canonical Ras GTPases, RGK GTPases have a low or absent GTPase activity, probably due to the non-conserved amino acid substitutions in the Switch I and G3 regions $[9,10]$. There are, however, indications that in the presence of nm23 - the only known RGK GTPase activating protein (GAP) - Rad and Gem have an enhanced GTPase activity [11]. Thus, the unique mechanism of GTP hydrolyses remains to be determined for RGK 
proteins. While most Ras GTPases undergo lipid modifications that help anchor them to the membrane, RGK proteins have extended $\mathrm{C}$-termini that take on this role, as well as serve as hubs, together with the N-termini, for interactions with other proteins, such as calmodulin $[7,12,13]$.

RGK proteins have two known functions: shaping cytoskeletal dynamics and inhibiting $\mathrm{HVA} \mathrm{Ca}^{2+}$ channels [14]. The two RGK functions can be regulated separately, so that RGK modification of cytoskeletal reorganization, but not inhibition of HVA $\mathrm{Ca}^{2+}$ channels, is attenuated by dephosphorylation of certain RGK residues [15,16]. Recent findings, however, have revealed $\mathrm{Ca}_{\mathrm{v}} \alpha_{1}$ as a point of convergence for the two functions. Namely, RGK binding to VGCCs seems to be critical for regulating cytoskeletal dynamics and dendritic arborization of nerve cells [17].

\section{RGKs inhibit $\mathrm{Ca}_{\mathrm{v}} 1$ and $\mathrm{Ca}_{\mathrm{v}} 2$ voltage-gated $\mathrm{Ca}^{2+}$ channels}

In a yeast two hybrid screen designed to identify novel $\mathrm{Ca}_{\mathrm{v}} \beta$ binding partners in $\beta$-pancreatic cells, Beguin et al. [18] identified Gem. Its coexpression with L-type channels $\mathrm{Ca}_{\mathrm{v}} 1.2$ and $\mathrm{Ca}_{\mathrm{v}} 1.3$, in the presence of $\mathrm{Ca}_{\mathrm{v}} \beta$, led to a dramatic inhibition of currents. The related monomeric GTPase RIN failed to reproduce this inhibition, suggesting that inhibition by Gem was specific. Ever since, many groups have demonstrated direct binding between all RGK proteins and all $\mathrm{Ca}_{\mathrm{v}} \beta$ subunits, as well as almost complete inhibition of all $\mathrm{Ca}_{\mathrm{v}} 1$ and $\mathrm{Ca}_{\mathrm{v}} 2$ channels, in a variety of expression systems $[1,5,14,18-30]$. As we now discuss, RGKs can inhibit both channel surface expression and gating, and in many cases, these two mechanisms act in concert (Figure 2).

\subsection{RGK proteins can inhibit channel surface expres- sion}

By analyzing membrane surface expression of extracellularly HA-tagged $\mathrm{Ca}_{\mathrm{v}} 1.2$ channels, Beguin et al. [18,20,31] showed that all RGKs decrease surface expression of L-type channels in PC12 or HEK293 cells.

Other examples exist (Table 1), where, to name two, viral transduction of Rad into guinea pig cardiomyocytes decreases $\mathrm{Ca}_{\mathrm{v}} 1.2$ surface expression [29], and Gem decreases $\mathrm{Ca}_{\mathrm{v}} 1.2$ channel localization at the membrane of tsA201 cells [33]. Other investigators, however, showed that neither Rem nor Rem2 inhibited $\mathrm{Ca}_{\mathrm{v}} 1.2$ channel surface expression in adult guinea pig heart cells or MIN6 cells, respectively. Rather, inhibition of membrane-resident channels took place $[25,34]$. In addition, Rem 2 did not inhibit the surface expression of N-type calcium channels in tsA cells, at a time when calcium currents were dramatically reduced [22].

A reconciliation between these disparate findings was offered by the Colecraft group, which used quantum dots and cell sorting analyses of surface-labeled $\mathrm{Ca}_{\mathrm{v}} 1.2$ channels, to screen thousands of HEK 293 cells [1]. As it turned out, Rem partially reduced surface expression of $\mathrm{Ca}_{\mathrm{v}} 1.2$ to $\sim 40 \%$. Since $\mathrm{Ca}_{\mathrm{v}} 1.2$ currents were completely inhibited, this
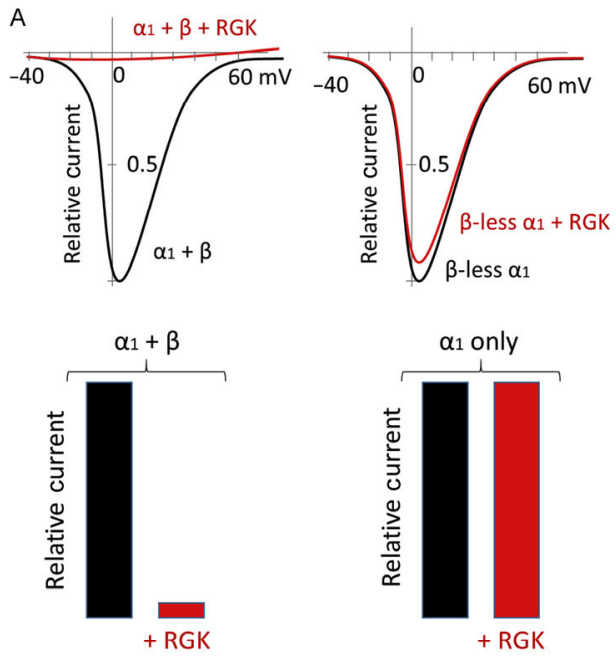
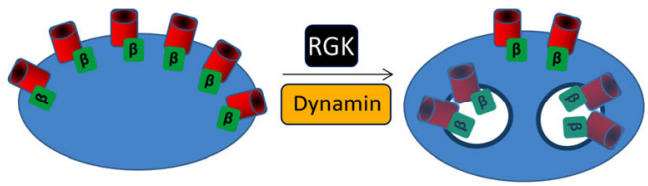

Closed

C

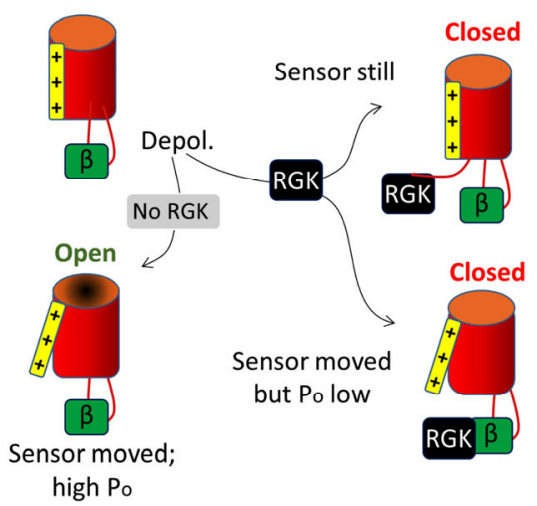

Figure 2 Mechanisms of RGK-mediated inhibition of VGCCs. A, RGKs inhibit VGCC current completely and this inhibition is dependent on the presence of a $\mathrm{Ca}^{2+}$ channel $\beta$ subunit. Thus, $\beta$-less channels, which we could generate in macropatches [6], are insensitive to RGK inhibition. B, RGKs exert a dynamin-mediated inhibition of VGCC surface expression. This inhibition depends on RGK-Ca $\beta$ binding. C, Two modes of RGK inhibition of membrane-resident VGCCs. The left two panels show normal channel opening upon depolarization (Depol.) In the presence of RGK (right two panels), the voltage sensor movement can be blocked, which may not require RGK-Ca $a_{v} \beta$ binding, or the voltage sensor may be free but channel $\mathrm{P}_{\mathrm{o}}$ is decreased. The latter requires RGK-Ca $\beta$ binding [13]. 
Table 1 RGK-mediated inhibition of VGCC surface expression

\begin{tabular}{|c|c|c|c|c|}
\hline RGK & VGCC & Mechanism & Tissue/Cells & Refs \\
\hline \multirow[b]{2}{*}{$\operatorname{Rad}$} & L-type (Cav1.2) & Decreases membrane fraction of channels. & $\begin{array}{l}\text { Native guinea pig } \\
\text { cardio-myocytes }\end{array}$ & [29] \\
\hline & Native PC12 VGCC & $\begin{array}{l}\text { Prevents VGCC surface expression through interac- } \\
\text { tion with Cav } \beta \text {. Subcellular distribution of RGK } \\
\text { controlled by CaM and } 14-3-3 \text { binding. Binds to and } \\
\text { sequesters Cav } \beta \text { to the nucleus. } \\
\text { Interaction with Cav } \beta \text { did not require CaM or } 14-3-3 \\
\text { binding. }\end{array}$ & $\begin{array}{l}\text { COS-1 cells for } \beta \text {-subunit } \\
\text { interaction, PC12 cells for } \\
\text { current, HEK-293T cells }\end{array}$ & [21] \\
\hline \multirow{3}{*}{ Rem } & \multirow{3}{*}{ L-type (Cav1.2) } & $\begin{array}{l}\text { Binding to Cav } \beta \text { to decreases forward trafficking of } \\
\text { channels and enhances dynamin-dependent backward } \\
\text { trafficking of channels. }\end{array}$ & HEK 293 cells & [2] \\
\hline & & $\begin{array}{c}\text { Controls VGCC membrane trafficking in response to } \\
\alpha_{1} \text {-adrenergic signaling. }\end{array}$ & $\begin{array}{l}\text { Neonatal rat ventricular } \\
\text { myocytes, HEK293T }\end{array}$ & [32] \\
\hline & & $\begin{array}{l}\text { Enhances dynamin-mediated endocytosis, which is } \\
\operatorname{Cav} \beta \text { binding-dependent. }\end{array}$ & HEK 293 cells & [1] \\
\hline Rem2 & & No report of inhibition of surface expression. & & \\
\hline \multirow[t]{2}{*}{ Gem/Kir } & L-type (Cav1.2) & $\begin{array}{l}\text { Decreases surface expression in a } \\
\text { calmodulin-dependent manner. }\end{array}$ & \multirow{2}{*}{$\begin{array}{l}\text { Xenopus oocytes BHK cells } \\
\text { and HEK } 293 \text { cells }\end{array}$} & \multirow{2}{*}[18]{} \\
\hline & L-type (Cav1.3) & $\begin{array}{l}\text { Decreases surface expression in a } \\
\text { calmodulin-dependent manner. }\end{array}$ & & \\
\hline
\end{tabular}

suggested that both inhibition of surface expression and inhibition of membrane-resident channels took place. Furthermore, the reduction of surface expression was dependent on dynamin, a molecular motor that promotes endocytosis. Thus, in the presence of Rem, a dominant negative dynamin construct was able to restore $\mathrm{Ca}_{\mathrm{v}} 1.2$ surface expression to normal levels [1]. This suggests that RGK proteins likely exert their effect on backward, not forward protein trafficking. In addition, this finding provides a link between RGKs' two known functions, i.e., regulation of cytoskeletal dynamics and inhibition of VGCCs. This experiment was remarkable for another reason: cells expressing Rem and the dominant negative dynamin still had strongly reduced VGCC currents, suggesting that membrane-resident channels were inhibited via an alternative mechanism. Similar dual mechanisms were also found for Rem2 inhibition of $\mathrm{Ca}_{\mathrm{v}} 1.2$ [2]. Thus, we now know that RGK proteins inhibit VGCCs simultaneously using a slow, trafficking-dependent mechanism and a fast mechanism that inhibits membrane-resident channels (see below and Figure 2).

\subsection{All RGK proteins can inhibit membrane-resident calcium channels}

The Andres and Ikeda groups first showed that RGK proteins can inhibit VGCCs without decreasing channel surface expression. Thus, Rem inhibited L-type currents in $\beta$-pancreatic cells and Rem 2 inhibited N-type currents in neurons, both without affecting channel surface expression $[22,25]$. However, the first direct evidence that RGK proteins can inhibit membrane-resident channels came from studies in macropatches. We coexpressed $\mathrm{Ca}_{\mathrm{v}} 2.1$ channels with $\mathrm{Ca}_{\mathrm{v}} \beta_{3}$ in Xenopus oocytes and excised large membrane patches containing these channel complexes. Application of a purified Gem protein to the intracellular face of the macropatches elicited partially reversible channel inhibition, demonstrating unequivocally that membrane-resident channels can be inhibited [6]. In addition, the speed of inhibition was relatively fast, reaching a maximum within $3 \mathrm{~min}$ of Gem application. Similarly, Colecraft and colleagues [30] showed that L- and N-type channels could be inhibited minutes within inducing a genetically modified Rem to translocate from the cytoplasm to the membrane.

How are membrane-resident channels inhibited? The Colecraft group demonstrated that Rem employs at least two separate mechanisms for the inhibition of membrane-resident channels: immobilizing the voltage sensor and decreasing channel open probability $\left(\mathrm{P}_{\mathrm{o}}\right.$, Table 2$)$ [1].

In the case of reducing voltage sensor movement, Yang et al. [1] used a clever tactic where they compared, on the one hand, the effect of Rem on gating currents (which reflects both the number of channels on the membrane and the mobility of their charged voltage sensors), and on the other hand, the effect of Rem on reducing the number of membrane-resident channels in flow cytometry experiments. This comparison revealed that Rem immobilizes voltage sensor movement of $\mathrm{Ca}_{\mathrm{v}} 1.2$ channels. Thus, in the presence of Rem, as well as the dominant negative dynamin mutant that rescues channel surface expression, gating currents were still reduced. This indicates that voltage sensor movement is obstructed in the presence of Rem and establishes a new mechanism of RGK inhibition of VGCCs. Similar reduction of voltage sensor movement may be exerted by Rad, but not Rem, on native $\mathrm{Ca}_{\mathrm{v}} 1.1$ skeletal muscle channels [35]. However, this has not been differentiated from a possible reduction in the number of available channels on the membrane. Finally, a recent report studying $\mathrm{Ca}_{\mathrm{v}} 1.2$ currents in cardiac myocytes from Rad knockout 
Table 2 RGK-mediated inhibition of membrane-resident VGCCs

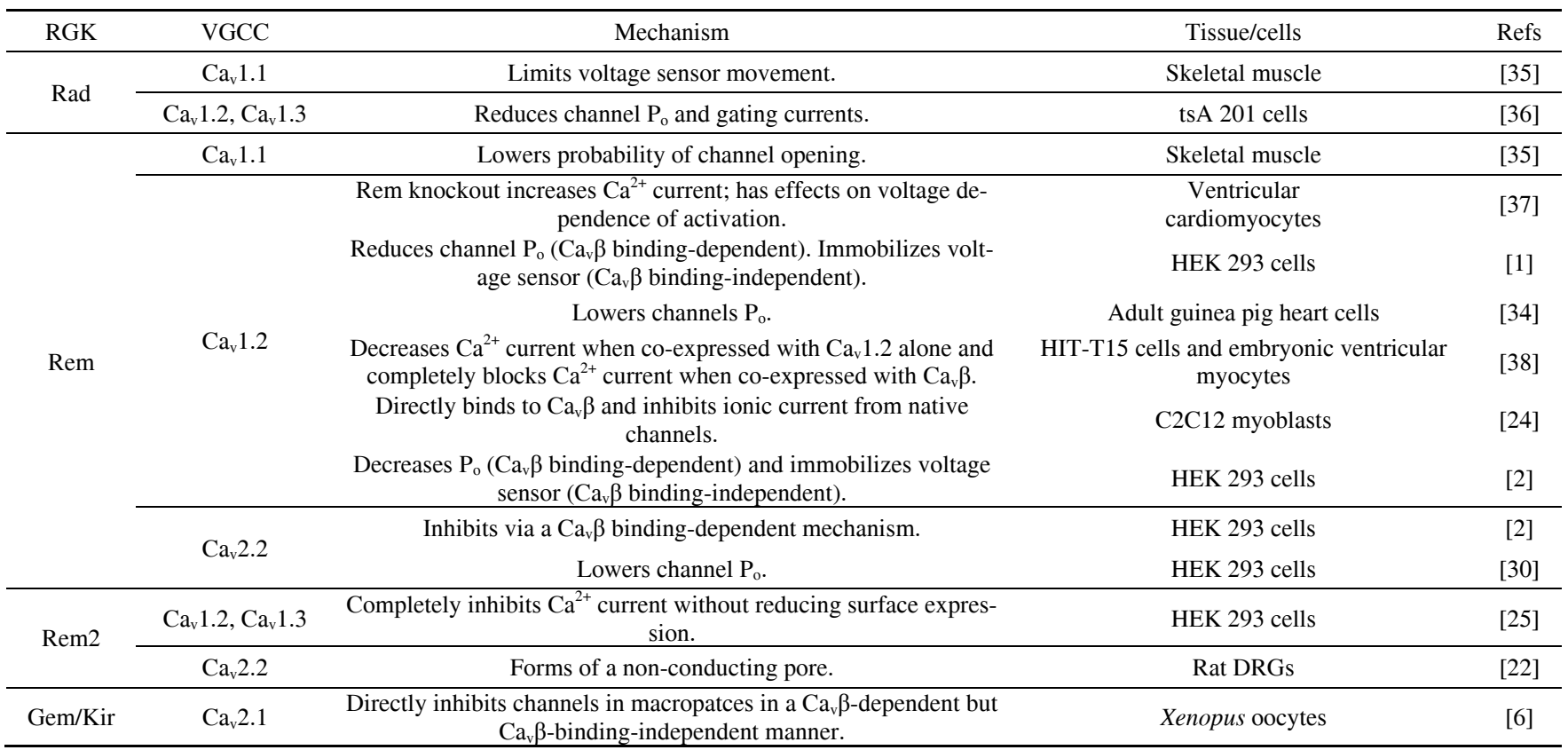

mice found that $\mathrm{Ca}_{\mathrm{v}} 1.2$ activation is shifted to more negative voltages (channels are easier to open), which is consistent with a retarding effect of Rad on voltage sensor movement. It remains to be determined how universal this effect is [39].

Interestingly, Gem and Rem2 do not seem to inhibit voltage sensor movement in $\mathrm{Ca}_{\mathrm{v}} 1.2$ channels. As will be discussed later, this difference is thought to result from their inability to bind to the channel's N-terminus [2]. The mode of inhibition in this case likely involves a decrease in surface expression coupled with a decrease in channel $P_{o}[1,2]$. Indeed, the comparison between $\mathrm{Ca}_{\mathrm{v}} 1.2$ gating currents and tail currents (the latter quantify the total ionic flow through open channels), revealed that channel $P_{o}$ is reduced in the presence of Rem [2]. Similarly, Rem2 was found to inhibit $\mathrm{Ca}_{\mathrm{v}} 2.2$ channels by rendering them nonconducting, the molecular mechanism of which is yet to be studied [22]. It would be interesting to perform single channel recordings to gain deeper insight into the mechanism of $\mathrm{P}_{\mathrm{o}}$ reduction.

\section{The role of $\mathrm{Ca}_{\mathbf{v}} \beta$ in RGK inhibition of VGCCs}

RGK inhibition of VGCCs is multifaceted, affecting the surface expression and biophysical properties of membrane-resident channels. But regardless of the mechanism, the presence of $\mathrm{Ca}_{\mathrm{v}} \beta$ is required for all forms of inhibition. However, RGK- $\mathrm{Ca}_{\mathrm{v}} \beta$ binding is important for some but not all forms of inhibition, as we discuss below.

\subsection{RGK-Ca $\beta$ binding}

RGK proteins interact directly with $\mathrm{Ca}_{\mathrm{v}} \beta$ both in vitro and in cells $[5,14,18,20,21,23,25-27,30,31,40]$, and this interaction is promiscuous whereby any RGK protein can interact with any full-length $\mathrm{Ca}_{\mathrm{v}} \beta$. This binding was initially proposed to inhibit VGCCs by competing $\mathrm{Ca}_{\mathrm{v}} \beta$ away from the calcium channel complex and sequestering $\mathrm{Ca}_{\mathrm{v}} \beta$ into the nucleus [31]. But we now know that this is an unlikely mechanism of inhibition for several reasons. First, when a nuclear export signal is engineered into Rem to prevent it from entering the nucleus and sequestering $\mathrm{Ca}_{\mathrm{v}} \beta$ with it, it was still able to inhibit VGCCs [1]. Second, a structural model of the Gem-Ca $\beta_{3} \beta_{3}$ interaction has been developed using homology modeling [40] based on $\mathrm{Ca}_{\mathrm{v}} \beta$ crystal structures [41-43] and a structure of GDP-bound Gem (PDB $2 \mathrm{G} 3 \mathrm{Y}$ ), as well as on systematic mutagenesis analysis. This model shows that Gem binds to the $\beta_{3}$ GK domain at a site distinct from the AID-binding pocket, with residues D194, D270 and D272 in $\beta_{3}$ and R196, V223 and H225 in Gem critical for this interaction (Figure 3 , red residues).

Thus, it is unlikely that RGK-Ca $\beta$ and $\mathrm{Ca}_{v} \beta-\mathrm{Ca}_{\mathrm{v}} \alpha_{1}$ bindings are mutually exclusive. Supporting this notion, mutating these critical residues individually or in combination severely weakens or abolishes in vitro binding of Gem and $\beta_{3}[6,40]$, while preserving calcium channel modulation by $\beta_{3}$. Third, $\mathrm{Ca}_{\mathrm{v}} \alpha_{1}, \mathrm{Ca}_{\mathrm{v}} \beta$ and RGK proteins can form a trimeric complex in vitro and in cells $[5,6,14,30,40]$.

\section{2 $\mathrm{Ca}_{\mathrm{v}} \beta$ is required for inhibition}

Beguin et al. [18] first demonstrated the critical role of $\mathrm{Ca}_{\mathrm{v}} \beta$ in RGK inhibition: absent $\mathrm{Ca}_{\mathrm{v}} \beta$, L-type channels could not be inhibited by RGKs (Figure 2). This turned out to be the case for other VGCCs [18,24,28]. However, in the absence of $\mathrm{Ca}_{\mathrm{v}} \beta$, which is required for calcium channel surface ex- 


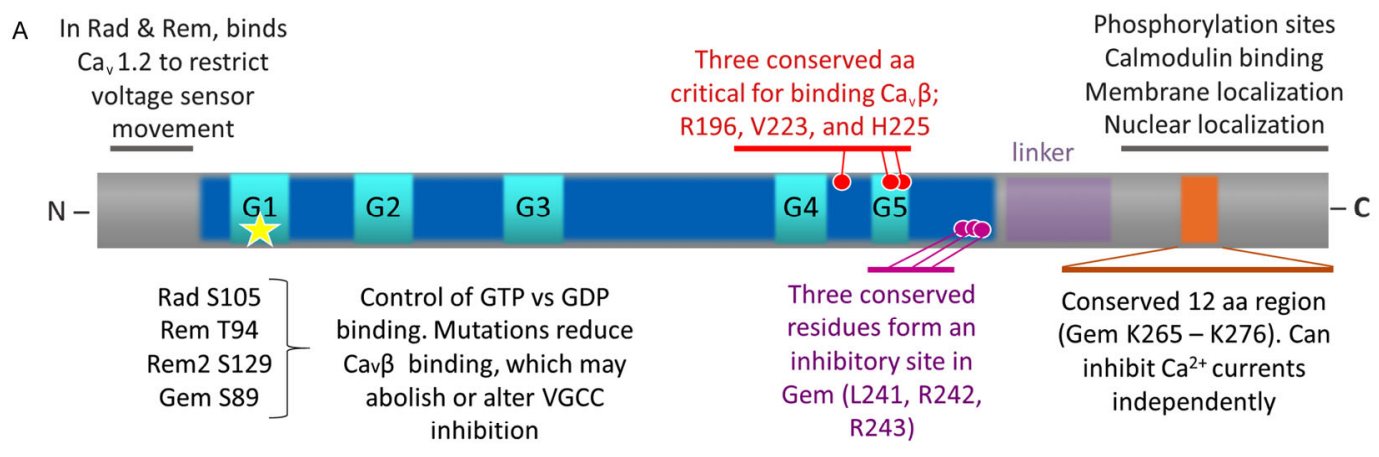

B
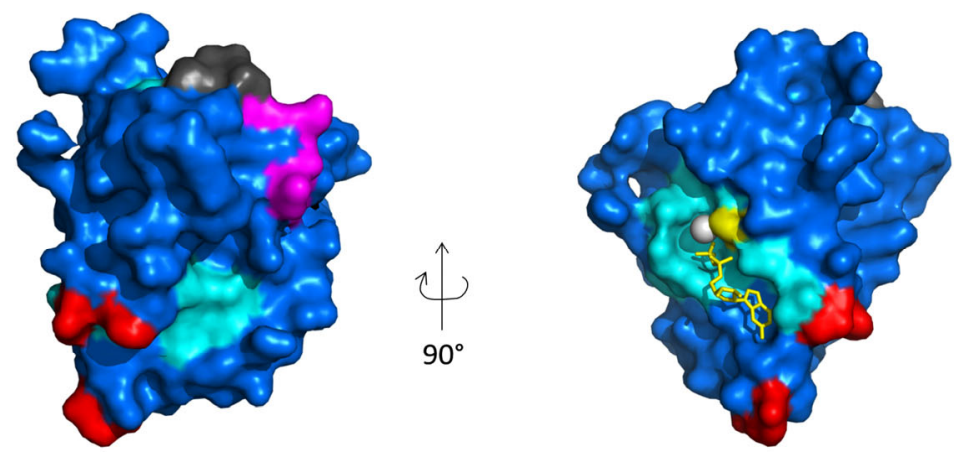

Figure 3 RGK domain organization and structure. A, Schematic diagram denoting the main regions of RGKs. The function of each domain, pertaining to some but not necessarily all RGKs, is indicated. The star indicates the location of a serine critical for GTP/GDP binding. Gray regions, N- and C-termini; blue, RGK core domain; cyan, G1-G5 regions; red and magenta circles, particular residues with the indicated functions; orange, a critical part of the C-terminus. B, The structure of Gem in complex with GDP (yellow sticks, PDB 2HT6). Gray, N-terminus; blue, Gem core; magenta, inhibitory site; red, $\mathrm{Ca}_{\mathrm{v}} \beta$ binding sites; cyan, G1, G3 and G5 (G2 and G4 are blue); yellow residue is Gem S89; white sphere, Mg ${ }^{2+}$ ion. The C-terminus is not included in the structure.

pression, VGCC currents are too small to be measured accurately $[3,4]$. To overcome this problem, and to provide a direct answer to whether $\mathrm{Ca}_{\mathrm{v}} \beta$ is required for inhibition, we mutated the ABP of $\mathrm{Ca}_{\mathrm{v}} \beta_{3}$ (M245A and L249A) to achieve two effects: (i) the mutation was mild enough to allow sufficient $\mathrm{Ca}_{\mathrm{v}} \beta_{3}-\mathrm{Ca}_{\mathrm{v}} \alpha_{1}$ binding to promote channel surface expression in Xenopus oocytes, in this case $\mathrm{Ca}_{\mathrm{v}} 2.1$; (ii) at the same time, the weakened $\mathrm{Ca}_{\mathrm{v}} \beta_{3}-\mathrm{Ca}_{\mathrm{v}} \alpha_{1}$ binding allowed us to later wash away this mutant $\mathrm{Ca}_{\mathrm{v}} \beta$ from a macropatch preparation, leaving $\beta$-less channels on the plasma membrane [6]. In support of previous findings, $\beta$-less channels could not be inhibited by purified Gem perfused onto the intracellular side of the macropatch. However, when WT $\mathrm{Ca}_{\mathrm{v}} \beta_{3}$ was perfused onto the macropatch first, Gem could now strongly inhibit the channels in a partially reversible manner. Thus, $\mathrm{Ca}_{\mathrm{v}} \beta$ is absolutely required for Gem inhibition of $\mathrm{Ca}_{\mathrm{v}} 2.1$ channels [6]. Consistent with this requirement, RGK proteins do not inhibit T-type $\mathrm{Ca}^{2+}$ channels, which do not associate with $\mathrm{Ca}_{\mathrm{v}} \beta$ nor require $\mathrm{Ca}_{\mathrm{v}} \beta$ for their activity $[6,22,24]$.

Is $\mathrm{Ca}_{\mathrm{v}} \beta$ required for inhibition because it anchors RGKs to the channel? To answer this question, we simultaneously mutated, based on model predictions and previous biochemical studies [6,40], three residues in each Gem and $\mathrm{Ca}_{\mathrm{v}} \beta_{3}$ to abolish their mutual interaction (creating Gem_ mut3 and $\beta 3$ mut3) [6]. We then tested for $\mathrm{Ca}_{\mathrm{v}} 2.1$ channel inhibition in whole oocytes and in macropatches. Strikingly, Gem_mut3 was able to inhibit $\mathrm{Ca}_{\mathrm{v}} 2.1$ channels expressed with $\beta 3$ _mut 3 , suggesting that the Gem-Ca $\beta_{3}$ interaction is not necessary for current inhibition. To reconcile this result with the finding that the presence of $\mathrm{Ca}_{\mathrm{v}} \beta$ is required for inhibition (as described above), we proposed a " $\beta$ priming model" where $\mathrm{Ca}_{\mathrm{v}} \beta$ is required to unmask an inhibitory site on $\mathrm{Ca}_{\mathrm{v}} \alpha_{1}$. This model implies that Gem can bind $\mathrm{Ca}_{\mathrm{v}} \alpha_{1}$ directly. Indeed, we found that Gem coimmunoprecipitated with $\mathrm{Ca}_{\mathrm{v}} 2.1$, even in the absence of $\mathrm{Ca}_{\mathrm{v}} \beta$, suggesting direct Gem-Ca 2.1 binding. Interestingly, Crump et al. [38] had found that a C-terminally truncated $\mathrm{Ca}_{\mathrm{v}} 1.2$ is relatively resistant to RGK inhibition, hinting that RGK-Ca $\mathrm{v}_{\mathrm{v}} 1.2$ interactions may occur. Thus, while $\mathrm{Ca}_{\mathrm{v}} \beta$ is necessary for some forms of RGK inhibition, $\mathrm{Ca}_{\mathrm{v}} \beta$-RGK binding may not be. Subsequent studies have identified both $\mathrm{Ca}_{\mathrm{v}} \beta-$ and $\mathrm{Ca}_{\mathrm{v}} \alpha_{1}$-binding dependent mechanisms of RGK inhibition $[1,2]$.

\subsection{RGK inhibition can be $\mathrm{Ca}_{\mathrm{v}} \boldsymbol{\beta}$-binding dependent and/or $\mathrm{Ca}_{\mathrm{v}} \alpha_{1}$-binding dependent}

To further investigate the effects of RGKs' multiple interactions with VGCCs, Colecraft and colleagues [2] expressed 
$\mathrm{Ca}_{\mathrm{v}} 1.2$ with a triple mutant $\mathrm{Ca}_{\mathrm{v}} \beta_{2 \mathrm{a}}$ that cannot interact with RGKs. Upon Rem coexpression, currents were still inhibited, albeit to a lesser extent than in the presence of $\mathrm{WT} \mathrm{Ca}_{\mathrm{v}} \beta$, suggesting that Rem inhibits $\mathrm{Ca}_{\mathrm{v}} 1.2$ channels using both $\mathrm{Ca}_{\mathrm{v}} \beta$-binding and $\mathrm{Ca}_{\mathrm{v}} \alpha_{1}$-binding dependent mechanisms. Further experiments revealed that the reduction of surface expression and of channel $\mathrm{P}_{\mathrm{o}}$ were critically dependent on binding to $\mathrm{Ca}_{\mathrm{v}} \beta$. Thus, translocation of a chemically sensitive Rem construct to the plasma membrane dramatically reduced channel $\mathrm{P}_{\mathrm{o}}$ only in the presence of a WT $\mathrm{Ca}_{\mathrm{v}} \beta$, but not the triple mutant $\mathrm{Ca}_{\mathrm{v}} \beta$. In contrast, the immobilization of voltage sensors seems to be dependent on Rem-Ca 1.2 binding, as it persisted in the presence of the triple mutant $\mathrm{Ca}_{\mathrm{v}} \beta$. Rad can also immobilize voltage sensor movement, and both Rad and Rem exert this effect by binding to the $\mathrm{Ca}_{\mathrm{v}} 1.2 \mathrm{~N}$-terminus [2]. On the other hand, Rem2 and Gem, which show no direct binding to $\mathrm{Ca}_{\mathrm{v}} 1.2$, rely only on $\mathrm{Ca}_{\mathrm{v}} \beta$-binding dependent mechanisms of inhibition: reduction in surface expression and channel $\mathrm{P}_{\mathrm{o}}$ [2]. In complementary experiments carried on $\mathrm{Ca}_{\mathrm{v}} 2.2$ channels, Rem used only $\mathrm{Ca}_{\mathrm{v}} \beta$-binding dependent mechanisms to inhibit $\mathrm{Ca}_{\mathrm{v}} 2.2$ [2]. These and the studies discussed earlier highlight the complexity of RGK regulation of VGCCs and demonstrate that the mechanisms of inhibition are RGK, $\mathrm{Ca}_{\mathrm{v}} \alpha_{1}$ and cell type specific.

\section{Molecular determinants of RGK inhibition}

\subsection{The $\mathrm{Ca}_{\mathrm{v}} \boldsymbol{\alpha}_{1} \mathrm{~N}$-terminus}

FRET, co-localization analyses and co-IP experiments show that Rem and Rad (but not Rem2 and Gem) bind to the N-terminus of $\mathrm{Ca}_{v} 1.2$, but not $\mathrm{Ca}_{\mathrm{v}} 2.2$ [2]. Functionally, this allows Rem and Rad to inhibit voltage sensor movement in $\mathrm{Ca}_{\mathrm{v}}$ 1.2. Remarkably, overexpression of the $\mathrm{Ca}_{\mathrm{v}} 1.2 \mathrm{~N}$ terminus can relieve Rem-mediated channel inhibition, albeit only incompletely since the $\mathrm{Ca}_{\mathrm{v}} \beta$-binding dependent mechanisms remain in place.

\subsection{The $\mathrm{Ca}_{\mathrm{v}} \boldsymbol{\alpha}_{1} \mathrm{C}$-terminus}

Yang et al. [2] performed extensive FRET, co-localization and co-IP analyses and showed that there is no appreciable binding between the $\mathrm{Ca}_{\mathrm{v}} 1.2 \mathrm{C}$-terminus and any of the four (tagged) RGKs. However, Pang et al. [44] suggested that Rem, Rem 2 and Rad bind to the C-terminus of $\mathrm{Ca}_{\mathrm{v}} 1.2$ in vitro. In addition, they showed that calmodulin overexpression can partially relieve RGK-mediated inhibition, suggesting that RGKs may be competing with calmodulin for the $\mathrm{Ca}_{v} \alpha_{1} \mathrm{C}$-terminus. The same group also found that $\mathrm{Ca}_{\mathrm{v}} 1.2$ with a truncated $\mathrm{C}$-terminus is relatively resistant to RGK inhibition [38]. While these results await confirmation, they highlight the growing consensus that RGK-mediated inhibition relies on both $\mathrm{Ca}_{\mathrm{v}} \beta$ - and $\mathrm{Ca}_{\mathrm{v}} \alpha_{1}$-binding mechanisms.

\subsection{The $\mathrm{Ca}_{v} \alpha_{1}$ IIS1-IIS3 region}

We were able to render $\mathrm{Ca}_{\mathrm{v}} 2.1$ insensitive to RGK inhibition by replacing its IIS1-IIS3 region with that of a T-type channel (Cav3.1) [6]. This finding suggests importance for this region in RGK-mediated inhibition, although the precise mechanism is unclear. We proposed that the IIS1-IIS3 region serves to transmit inhibition to the channel from the RGK protein and through $\mathrm{Ca}_{\mathrm{v}} \beta$, which is bound on the nearby I-II loop. Remarkably, T-type channels became RGK sensitive when their I-II loop, together with the IIS1-IIS3 region, were replaced with those of $\mathrm{Ca}_{\mathrm{v}} 2.1$ [6]. This was not the case when only the I-II loop was transplanted, even though $\mathrm{Ca}_{\mathrm{v}} \beta$ could bind to this chimeric channel and modulate its gating, suggesting that $\mathrm{Ca}_{\mathrm{v}} \beta$ is not sufficient for conferring RGK sensitivity and that the IIS1-IIS3 region of $\mathrm{Ca}_{\mathrm{v}} \alpha_{1}$ is critical.

\subsection{The RGK C-terminus}

Several groups have demonstrated that truncating the RGK C-terminus abolishes their ability to inhibit VGCCs $[1,6,22-24,30,34]$. There may be multiple explanations for this. First, the C-terminus itself may be the inhibitory domain of RGK. Leyris et al. [27] showed that the Gem C-terminus can inhibit $\mathrm{Ca}_{\mathrm{v}} 2.1$ channels in Xenopus oocytes. In addition, we performed extensive deletion analyses and found a 12 amino acid (aa) C-terminal region of Gem that, when purified and applied to macropatches, can inhibit $\mathrm{Ca}_{\mathrm{v}} 2.1$ [45]. Interestingly, it was the amino acid content, not the sequence of amino acids that was critical. Though this region is conserved in other RGK C-termini, co-expression of Rem and Rem2 C-termini could not inhibit $\mathrm{Ca}_{\mathrm{v}} 1.2$ and $\mathrm{Ca}_{\mathrm{v}} 2.2$ channels $[22,23]$. Thus, the effect of this 12 aa fragment may be specific for $\mathrm{Ca}_{\mathrm{v}} 2.1$ channels. Interestingly, mutating this 12 aa site in full-length Gem is not sufficient to abolish inhibition, suggesting the existence of one or more additional inhibitory sites. As discussed below, a candidate inhibitory site has been found in the core region of Gem [45].

A more universal function for the RGK C-terminus in channel inhibition lies in the fact that it contains a polybasic motif used for membrane anchorage of RGKs [14,22,46]. Deleting or mutating the RGK C-terminus abolishes their membrane targeting as well as VGCC inhibition $[1,6,22-24,30,34]$. Thus, the main function of the RGK C-terminus may be to target RGKs to the membrane, where they can, in a higher effective concentration, inhibit VGCCs. In support of this notion, C-terminally truncated Rem and Rem 2 could regain their inhibitory function against $\mathrm{Ca}_{\mathrm{v}} 1.2$ and $\mathrm{Ca}_{\mathrm{v}} 2.2$ channels if they were fused to the membrane targeting sequence of an unrelated protein [22,23]. Interestingly, a mutant Rem (L271G) that is not targeted to the membrane is still capable of inhibiting $\mathrm{Ca}_{\mathrm{v}} 1.2$ channels, albeit incompletely $[1,31]$. Perhaps this is due to $\mathrm{Ca}_{\mathrm{v}} \beta$ act- 
ing as a membrane anchor for Rem.

A complicating factor in determining the precise role of the RGK C-terminus in VGCC inhibition is that it also contains calmodulin and 14-3-3 binding sites, phosphorylation sites and a nuclear localization signal [13]. The roles of those sites are not very clear. For example, we have found that mutating a calmodulin binding site in Gem (W269G) has no effect on $\mathrm{Ca}_{\mathrm{v}}$ 2.1-channel inhibition [45], while the same mutation impaired Gem inhibition of native VGCCs in PC12 cells (reviewed by [14,21]).

Finally, a recent study found that the final 11 residues of all RGK proteins are highly conserved across phyla, with a consensus sequence that can serve to differentiate between RGKs and other Ras-related GTPases. The function of this region, termed C-7 because of a ubiquitous cysteine seven residues from the end, has yet to be determined [47]. It is clear, however, that Gem inhibition of $\mathrm{Ca}_{\mathrm{v}} 2.1$ can proceed without it (see deletion constructs from [45]).

\subsection{The RGK N-terminus}

Beqollari et al. [35] recently identified the N-terminus of $\mathrm{Rad}$ as a critical molecular determinant of Rad-mediated reduction in voltage sensor movement of native $\mathrm{Ca}_{\mathrm{v}} 1.1$ channels from muscle. Thus, replacing the N-terminus of Rad with that of Rem, which has no effect on $\mathrm{Ca}_{\mathrm{v}} 1.1$ voltage sensors, abolished the inhibition of voltage sensor movement by the mutant Rad. On the other hand, the $\mathrm{N}$-terminus of Rem harbors a protein kinase D1 phosphorylation site that, when phosphorylated, may relieve Rem inhibition of $\mathrm{Ca}_{\mathrm{v}} 1.2$ and contribute to $\beta$-adrenergic signaling in the heart [32]. Finally, other studies have shown that the $\mathrm{N}$-termini of Gem and Rem2 do not contribute to $\mathrm{Ca}_{\mathrm{v}} 2.1$ or $\mathrm{Ca}_{\mathrm{v}} 2.2$ inhibition, respectively $[22,45]$.

\subsection{The RGK core region}

We and others have shown that the core region of Gem, without the $\mathrm{N}$ - and C-termini, is incapable of inhibiting $\mathrm{Ca}_{\mathrm{v}} 2.1$ channels; it requires at least membrane anchorage [1] or part of the C-terminus for inhibition [45]. But several C-terminal mutants could still inhibit channels, suggesting there was an inhibitory site in the RGK core. We have identified three conserved amino acids (Figure 3, magenta) in the core of RGK proteins (Gem L241, R242, R243), that may form part of an inhibitory site [45]. When mutated in full-length Gem, inhibition is not abolished, but when these three amino acids are mutated together with the C-terminal 12 aa region, all $\mathrm{Ca}_{\mathrm{v}} 2.1$ inhibition is lost. At the same time, Gem binding to $\mathrm{Ca}_{\mathrm{v}} \beta$ and Gem binding to $\mathrm{Ca}_{\mathrm{v}} \alpha_{1}$ are preserved. Thus, it appears that there are at least two inhibitory sites in Gem, one in the core region and one in the C-terminus, both contributing independently to Gem inhibition of $\mathrm{Ca}_{\mathrm{v}} 2.1$ [45].

\subsection{The RGK guanine-nucleotide binding domain}

RGKs can be GTP- or GDP-bound, and there are differences in the efficacy with which the two forms inhibit VGCCs. Several groups used mutations homologous to a mutation in Ras $\left(\operatorname{Ras}^{\mathrm{S} 17 \mathrm{~N}}\right.$ ), which decrease GTP binding, to examine the role of GTP binding in RGK inhibition of VGCCs. $\operatorname{Rad}^{\mathrm{S} 105 \mathrm{~N}}$ and $\mathrm{Gem}^{\mathrm{S} 89 \mathrm{~N}}$ mutants, which were preferentially GDP-bound, and Rem ${ }^{\mathrm{T} 94 \mathrm{~N}}$ and Rem $2^{\mathrm{S} 129 \mathrm{~N}}$, display reduced binding to $\mathrm{Ca}_{\mathrm{v}} \beta[20,21,31]$. Functionally, Gem ${ }^{\mathrm{S} 89 \mathrm{~N}}$ (Figure 3, yellow residue) could not inhibit VGCCs in sympathetic neurons [16], suggesting that inhibition may require GTP binding in this system. $\operatorname{Rem}^{\mathrm{T}}{ }^{\mathrm{N} N}$, on the other hand, could still inhibit $\mathrm{Ca}_{\mathrm{v}} 1.2$ channels expressed in HEK293 cells, but without impacting voltage sensor movement [1]. This is in contrast to results obtained in the heart, where Rem ${ }^{\mathrm{T} 94 \mathrm{~N}}$ could not inhibit $\mathrm{Ca}_{\mathrm{v}} 1.2$ currents, presumably because heart cells can inactivate GDP-bound Rem or prevent it from inhibiting $\mathrm{Ca}_{\mathrm{v}} 1.2$ channels [34]. Similarly mixed results were obtained for $\operatorname{Rad}^{\mathrm{S} 105 \mathrm{~N}}$, which could not inhibit $\mathrm{Ca}_{\mathrm{v}} 1.2$ channels in HEK 293 cells but increased native calcium currents in heart cells [29], suggesting it acted as a dominant negative molecule. Finally, Rem2 inhibition of VGCCs seems to be insensitive to the type of nucleotide bound [22]. Thus, Rem $2^{\text {S129N }}$ inhibited sympathetic neuron currents as strongly as WT Rem2. In addition, dialyzing sympathetic neurons that normally express Rem2, with GDP $\beta$ s, a non-hydrolysable form of GDP, had no effect on current inhibition.

\section{Physiological significance of RGK-mediated VGCC inhibition}

The physiological significance of VGCC inhibition by RGKs has been recently questioned [48]. This is because RGK GTPases have been implicated in many physiological processes that are, hitherto, unrelated to their function to inhibit VGCCs. These include, for example, effects on cell migration, morphogenesis, differentiation and apoptosisfunctions that are mostly carried out through RGK actions on Rho kinases, p53, cyclins and other molecules [13,48]. In addition, most studies use overexpression to study RGK-mediated VGCC inhibition. However, we discuss below several reports that clearly illustrate dramatic physiologically relevant effects following manipulations of endogenous RGK levels. Overexpression studies were reviewed elsewhere $[13,14,48,49]$.

\subsection{Heart}

It has been shown that dominant negative suppression of endogenous Rad in the heart increases L-type $\mathrm{Ca}^{2+}$ channel currents and action potential duration in cardiac cells and causes longer QT intervals and arrhythmias [29]. Calcium 
currents of cardiac myocytes from Rad knockout mice are significantly larger and have a negatively shifted activation curve (channels are easier to open) [39]. In addition, these mycocytes are relatively unresponsive to $\beta$-adrenergic modulation. Equally compelling studies show that cardiomyocytes from $\mathrm{Rem}^{-/-}$mice have a smaller twitch amplitude, underlined by calcium current densities that are $\sim 15 \%$ reduced compared to WT cardiomyocytes and activation that is shifted $\sim 4 \mathrm{mV}$ to more depolarized voltages [37]. Finally, Rem phosphorylation by Protein Kinase D1 can relieve VGCC inhibition in cardiac muscle, in a signaling pathway downstream of $\beta$-adrenergic stimulation [32]. These findings demonstrate a critical role for RGK-mediated VGCC inhibition in regulating cardiac function and homeostasis.

\subsection{Nerve}

Using RT-PCR and microarray analyses, Scamps et al. [50] demonstrated specific upregulation of Gem in dorsal root ganglia following neuronal injury. Furthermore, siRNA against endogenous Gem led to a 55\% upregulation of P/Q-type currents. The authors reported that Gem expression after injury functioned to specifically inhibit P/Q-type channels, which in turn inhibited neural branching and likely contributed to the homeostatic mechanisms triggered to promote plasticity and neuroregeneration. Interestingly, the mechanism by which Gem specifically targeted P/Q channels rather than the coexisting native $\mathrm{N}$-type channels seemed to involve a simple dosage effect, whereby P/Q channels were comparatively much more sensitive to Gem than N-type channels. This was demonstrated with a dose-response curve in Xenopus oocytes, where the levels of Gem expression could be carefully titrated by injecting different amounts of Gem RNA.

Recently, several reports have focused on the role of RGK proteins, in particular Rem2 [51] and Gem [17], in controlling neuronal morphology. In one study, the effects of the Timothy Syndrome (TS) mutation on dendritic arborization were investigated. TS is a cardiovascular and neurological disorder that causes death by the age of three, primarily due to cardiac arrest. In addition, $80 \%$ of TS patients also have autism. The disease is caused by a point mutation in $\mathrm{Ca}_{\mathrm{v}} 1.2$ that slows channel inactivation [52]. In a seminal study, Dolmetsch and colleagues [17] showed that neurons generated from TS patients (from their induced pluripotent stem cells) exhibited an activity-dependent reduction in dendritic arborization compared to WT cells (which showed an increase in dendritic arborization upon stimulation). Remarkably, Gem overexpression prevented the reduction in dendritic arborization of TS cells in a manner that required $\mathrm{Gem}-\mathrm{Ca}_{v} \beta$ binding. Intriguingly, both the reduced dendritic arborization and its reversal by $\mathrm{Gem}$ overexpression were observed with $\mathrm{TS} \mathrm{Ca}_{\mathrm{v}} 1.2$ channels that also had mutations blocking the channels' pore. Thus, Gem has to bind to the VGCC complex, but its alteration of den- dritic arborization uses a mechanism that is independent of VGCC channel inhibition. The authors proposed that Gem binding or recruitment to the TS channel was impaired, leading to an increased activity of Rho-kinase and a resultant inhibition of dendritic arborization, whereas in WT cells, Gem recruitment and binding to the channel is more efficient, Rho-kinase inhibition is stronger, and a more vibrant dendritic arborization is observed.

While this study and a similar one that studied Rem2 [51] show a major role for RGKs in altering cell morphology independent of VGCC inhibition, it does not exclude a significant role of VGCC inhibition in contributing to the autistic phenotype. We recently found that Gem inhibited TS currents much more weakly than it did WT Ca 1.2 currents [53]. Thus, while a role for $\mathrm{Ca}^{2+}$ ions may be excluded in the reduced dendritic arborization of TS cells, it cannot be disregarded in contributing to the overall autistic phenotype in TS patients. A recent combination of systems and computational approaches suggested $\mathrm{Ca}^{2+}$ as a central factor in the pathophysiology of autism [54].

Finally, a recent study from the Ikeda group suggested that both RGK binding to $\mathrm{Ca}_{\mathrm{v}} \beta$ as well as RGK inhibition of VGCCs is over 550 million years old. All three residues in both RGKs and $\mathrm{Ca}_{\mathrm{v}} \beta$ s involved in $\mathrm{Ca}_{\mathrm{v}} \beta$-RGK binding are nearly $100 \%$ conserved, and fruit flies as well as zebrafish RGK proteins can inhibit calcium channels of rat sympathetic neurons [47]. Thus, the RGK interaction with and inhibition of VGCCs originated prior to the deuterostome-protostome split and is likely to have physiological significance beyond heart, muscle and nerve functions.

\section{Future directions}

As much as the field of RGK regulation of VGCCs has grown, there are many tantalizing unanswered questions. Like chameleons, RGK proteins alter the mode of their inhibition of VGCCs depending on the cellular context and the $\mathrm{Ca}_{\mathrm{v}}$ channels they are paired with. It remains to be determined which cellular or experimental factors contribute to the observed discrepancies in the modes of RGK inhibition. These factors may include GTPase activating proteins such as nm23 and proteins that interact with VGCC subunits. New RGK binding partners may be identified through yeast two hybrid or other screens. Considering the newly described role of RGK proteins in shaping neuronal morphology [17,51], it would be interesting to identify further links between calcium channels and cytoskeletal reorganization. It would also be interesting to examine whether RGKs interact with synaptic proteins and regulate synaptic transmission, since RGKs have been identified as critical elements for synapse formation [55]. Furthermore, while studies with inducible RGK-mediated inhibition of $\mathrm{Ca}_{\mathrm{v}}$ channels have shown promising results [30], studies with inducible knockouts are lacking in this field. Such studies 
will likely uncover yet unknown roles of RGK proteins in both physiological and pathological settings.

This work was supported by the Dyson College 2014 Faculty Summer Research Grant Program (Zafir Buraei), Dyson College 2014 Summer Undergraduate Student-Faculty Research Award (Zafir Buraei and Sukhjinder Kaur), the National Key Basic Research Program of China (2014CB910301 to Yang Jian), the Top Talents Program of Yunnan Province, China (Yang Jian), and the US National Institutes of Health (NS053494 to Yang Jian).

1 Yang T, Xu X, Kernan T, Wu V, Colecraft HM. Rem, a member of the RGK GTPases, inhibits recombinant $\mathrm{Ca}_{\mathrm{v}} 1.2$ channels using multiple mechanisms that require distinct conformations of the GTPase. J Physiol (Lond), 2010, 588: 1665-1681

2 Yang T, Puckerin A, Colecraft HM. Distinct RGK GTPases differentially use $\alpha 1$ - and auxiliary $\beta$-binding-dependent mechanisms to inhibit $\mathrm{Ca}_{\mathrm{v}} 1.2 / \mathrm{Ca}_{\mathrm{v}} 2.2$ channels. PLoS One, 2012, 7: e37079

3 Buraei Z, Yang J. The $\beta$ subunit of voltage-gated $\mathrm{Ca}^{2+}$ channels. Physiol Rev, 2010, 90: 1461-1506

4 Buraei Z, Yang J. Structure and function of the $\beta$ subunit of voltage-gated $\mathrm{Ca}^{2+}$ channels. Biochim Biophys Acta, 2013, 1828: 1530-1540

5 Finlin BS, Correll RN, Pang C, Crump SM, Satin J, Andres DA. Analysis of the complex between $\mathrm{Ca}^{2+}$ channel beta-subunit and the Rem GTPase. J Biol Chem, 2006, 281: 23557-23566

6 Fan M, Buraei Z, Luo HR, Levenson-Palmer R, Yang J. Direct inhibition of P/Q-type voltage-gated $\mathrm{Ca}^{2+}$ channels by Gem does not require a direct Gem/Cavbeta interaction. Proc Natl Acad Sci USA, 2010, 107: 14887-14892

7 Neely A, Hidalgo P. Structure-function of proteins interacting with the $\alpha 1$ pore-forming subunit of high-voltage-activated calcium channels. Front Physiol, 2014, 5: 209

8 Reynet C, Kahn CR. Rad: a member of the Ras family overexpressed in muscle of type II diabetic humans. Science, 1993, 262: 1441-1444

9 Splingard A, Ménétrey J, Perderiset M, Cicolari J, Regazzoni K, Hamoudi F, Cabanié L, El Marjou A, Wells A, Houdusse A, de Gunzburg J. Biochemical and structural characterization of the Gem GTPase. J Biol Chem, 2007, 282: 1905-1915

10 Yanuar A, Sakurai S, Kitano K, Hakoshima T. Crystal structure of human Rad GTPase of the RGK-family. Genes Cells, 2006, 11: 961-968

11 Moyers JS, Zhu J, Kahn CR. Effects of phosphorylation on function of the Rad GTPase. Biochem J, 1998, 333: 609-614

12 Moyers JS, Bilan PJ, Zhu J, Kahn CR. Rad and Rad-related GTPases interact with calmodulin and calmodulin-dependent protein kinase II. J Biol Chem, 1997, 272: 11832-11839

13 Yang T, Colecraft HM. Regulation of voltage-dependent calcium channels by RGK proteins. Biochim Biophys Acta, 2013, 1828: 1644-1654

14 Correll RN, Pang C, Niedowicz DM, Finlin BS, Andres DA. The RGK family of GTP-binding proteins: regulators of voltage-dependent calcium channels and cytoskeleton remodeling. Cell Signal, 2008, 20: 292-300

15 Finlin BS, Andres DA. Phosphorylation-dependent association of the Ras-related GTP-binding protein Rem with 14-3-3 proteins. Arch Biochem Biophys, 1999, 368: 401-412

16 Ward Y, Spinelli B, Quon MJ, Chen H, Ikeda SR, Kelly K. Phosphorylation of critical serine residues in Gem separates cytoskeletal reorganization from down-regulation of calcium channel activity. Mol Cell Biol, 2004, 24: 651-661

17 Krey JF, Paşca SP, Shcheglovitov A, Yazawa M, Schwemberger R, Rasmusson R, Dolmetsch RE. Timothy syndrome is associated with activity-dependent dendritic retraction in rodent and human neurons. Nat Neurosci, 2013, 16: 201-209

18 Béguin P, Nagashima K, Gonoi T, Shibasaki T, Takahashi K,
Kashima Y, Ozaki N, Geering K, Iwanaga T, Seino S. Regulation of $\mathrm{Ca}^{2+}$ channel expression at the cell surface by the small G-protein kir/Gem. Nature, 2001, 411: 701-706

19 Bannister RA, Colecraft HM, Beam KG. Rem inhibits skeletal muscle EC coupling by reducing the number of functional L-type $\mathrm{Ca}^{2+}$ channels. Biophys J, 2008, 94: 2631-2638

20 Béguin P, Mahalakshmi RN, Nagashima K, Cher DH, Kuwamura N, Yamada Y, Seino Y, Hunziker W. Roles of 14-3-3 and calmodulin binding in subcellular localization and function of the small G-protein Rem2. Biochem J, 2005, 390: 67-75

21 Béguin P, Mahalakshmi RN, Nagashima K, Cher DH, Takahashi A, Yamada Y, Seino Y, Hunziker W. 14-3-3 and calmodulin control subcellular distribution of Kir/Gem and its regulation of cell shape and calcium channel activity. J Cell Sci, 2005, 118: 1923-1934

22 Chen H, Puhl HL, Niu SL, Mitchell DC, Ikeda SR. Expression of Rem2, an RGK family small GTPase, reduces N-type calcium current without affecting channel surface density. J Neurosci, 2005, 25: 9762-9772

23 Correll RN, Pang C, Finlin BS, Dailey AM, Satin J, Andres DA. Plasma membrane targeting is essential for rem-mediated $\mathrm{Ca}^{2+}$ channel inhibition. J Biol Chem, 2007, 282: 28431-28440

24 Finlin BS, Crump SM, Satin J, Andres DA. Regulation of voltage-gated calcium channel activity by the Rem and Rad GTPases. Proc Natl Acad Sci USA, 2003, 100: 14469-14474

25 Finlin BS, Mosley AL, Crump SM, Correll RN, Ozcan S, Satin J, Andres DA. Regulation of L-type $\mathrm{Ca}^{2+}$ channel activity and insulin secretion by the Rem2 GTPase. J Biol Chem, 2005, 280: 41864-41871

26 Flynn R, Chen L, Hameed S, Spafford JD, Zamponi GW. Molecular determinants of Rem2 regulation of N-type calcium channels. Biochem Biophys Res Commun, 2008, 368: 827-831

27 Leyris JP, Gondeau C, Charnet A, Delattre C, Rousset M, Cens T, Charnet P. RGK GTPase-dependent $\mathrm{Ca}_{\mathrm{v}} 2.1 \mathrm{Ca}^{2+}$ channel inhibition is independent of $\mathrm{Ca}_{\mathrm{v}}$ beta-subunit-induced current potentiation. FASEB J, 2009, 23: 2627-2638

28 Seu L, Pitt GS. Dose-dependent and isoform-specific modulation of $\mathrm{Ca}^{2+}$ channels by RGK GTPases. J Gen Physiol, 2006, 128: 605-613

29 Yada H, Murata M, Shimoda K, Yuasa S, Kawaguchi H, Ieda M, Adachi T, Murata M, Ogawa S, Fukuda K. Dominant negative suppression of Rad leads to QT prolongation and causes ventricular arrhythmias via modulation of L-type $\mathrm{Ca}^{2+}$ channels in the heart. Circ Res, 2007, 101: 69-77

30 Yang T, Suhail Y, Dalton S, Kernan T, Colecraft HM. Genetically encoded molecules for inducibly inactivating $\mathrm{Ca}_{\mathrm{v}}$ channels. Nat Chem Biol, 2007, 3: 795-804

31 Béguin P, Mahalakshmi RN, Nagashima K, Cher DH, Ikeda H, Yamada Y, Seino Y, Hunziker W. Nuclear sequestration of beta-subunits by Rad and Rem is controlled by 14-3-3 and calmodulin and reveals a novel mechanism for $\mathrm{Ca}^{2+}$ channel regulation. J Mol Biol, 2006, 355: 34-46

32 Jhun BS, O-Uchi J, Wang W, Ha CH, Zhao J, Kim JY, Wong C, Dirksen RT, Lopes CM, Jin ZG. Adrenergic signaling controls RGK-dependent trafficking of cardiac voltage-gated L-type $\mathrm{Ca}^{2+}$ channels through PKD1. Circ Res, 2012, 110: 59-70

33 Sasaki T, Shibasaki T, Béguin P, Nagashima K, Miyazaki M, Seino S. Direct inhibition of the interaction between alpha-interaction domain and beta-interaction domain of voltage-dependent $\mathrm{Ca}^{2+}$ channels by Gem. J Biol Chem, 2005, 280: 9308-9312

34 Xu X, Marx SO, Colecraft HM. Molecular mechanisms, and selective pharmacological rescue, of Rem-inhibited CaV1.2 channels in heart. Circ Res, 2010, 107: 620-630

35 Beqollari D, Romberg CF, Meza U, Papadopoulos S, Bannister RA. Differential effects of RGK proteins on L-type channel function in adult mouse skeletal muscle. Biophys J, 2014, 106: 1950-1957

36 Meza U, Beqollari D, Romberg C F, Papadopoulos S, Bannister RA. Potent inhibition of L-type $\mathrm{Ca}^{2+}$ currents by a Rad variant associated with congestive heart failure. Biochem Biophys Res Commun, 2013, 439: $270-274$ 
37 Magyar J, Kiper CE, Sievert G, Cai W, Shi GX, Crump SM, Li L, Niederer S, Smith N, Andres DA, Satin J. Rem-GTPase regulates cardiac myocyte L-type calcium current. Channels (Austin), 2012, 6: 166-173

38 Crump SM, Correll RN, Schroder EA, Lester WC, Finlin BS, Andres DA, Satin J. L-type calcium channel $\alpha$-subunit and protein kinase inhibitors modulate Rem-mediated regulation of current. Am J Physiol Heart Circ Physiol, 2006, 291: H1959-1971

39 Manning JR, Yin G, Kaminski CN, Magyar J, Feng HZ, Penn J, Sievert G, Thompson K, Jin JP, Andres DA, Satin J. Rad GTPase deletion increases L-type calcium channel current leading to increased cardiac contraction. J Am Heart Assoc, 2013, 2: e000459

40 Béguin P, Ng YJ, Krause C, Mahalakshmi RN, Ng MY, Hunziker W. RGK small GTP-binding proteins interact with the nucleotide kinase domain of $\mathrm{Ca}^{2+}$-channel $\beta$-subunits via an uncommon effector binding domain. J Biol Chem, 2007, 282: 11509-11520

41 Chen YH, Li MH, Zhang Y, He LL, Yamada Y, Fitzmaurice A, Shen Y, Zhang H, Tong L, Yang J. Structural basis of the $\alpha 1-\beta$ subunit interaction of voltage-gated $\mathrm{Ca}^{2+}$ channels. Nature, 2004, 429: 675-680

42 Opatowsky Y, Chen CC, Campbell KP, Hirsch JA. Structural analysis of the voltage-dependent calcium channel $\beta$ subunit functional core and its complex with the $\alpha 1$ interaction domain. Neuron, 2004, 42: 387-399

43 van Petegem F, Clark KA, Chatelain FC, Minor DL. Structure of a complex between a voltage-gated calcium channel $\beta$-subunit and an $\alpha$-subunit domain. Nature, 2004, 429: 671-675

44 Pang C, Crump SM, Jin L, Correll RN, Finlin BS, Satin J, Andres DA. Rem GTPase interacts with the proximal $\mathrm{Ca}_{\mathrm{v}} 1.2 \mathrm{C}$-terminus and modulates calcium-dependent channel inactivation. Channels (Austin), 2010, 4: 192-202

45 Fan M, Zhang WK, Buraei Z, Yang J. Molecular determinants of Gem protein inhibition of P/Q-type $\mathrm{Ca}^{2+}$ channels. J Biol Chem, 2012, 287: 22749-22758

46 Heo WD, Inoue T, Park WS, Kim ML, Park BO, Wandless TJ, Meyer T. PI(3,4,5)P3 and PI(4,5)P2 lipids target proteins with polybasic clusters to the plasma membrane. Science, 2006, 314: 1458-1461

47 Puhl HL 3rd, Lu VB, Won YJ, Sasson Y, Hirsch JA, Ono F, Ikeda SR. Ancient origins of RGK protein function: modulation of voltage-gated calcium channels preceded the protostome and deuterostome split. PLoS One, 2014, 9: e100694

48 Ghiretti AE, Paradis S. Molecular mechanisms of activity-dependent changes in dendritic morphology: role of RGK proteins. Trends Neurosci, 2014, doi:10.1016/j.tins.2014.05.003

49 Flynn R, Zamponi GW. Regulation of calcium channels by RGK proteins. Channels (Austin), 2010, 4: 434-439

50 Scamps F, Sangari S, Bowerman M, Rousset M, Bellis M, Cens T, Charnet P. Nerve injury induces a Gem-GTPase-dependent downregulation of P/Q-type $\mathrm{Ca}^{2+}$ channels contributing to neurite plasticity in dorsal root ganglion neurons. Pflugers Arch Eur J Physiol, 2014, doi:10.1007/s00424-014-1520-4

51 Ghiretti AE, Moore AR, Brenner RG, Chen LF, West AE, Lau NC, Van Hooser SD, Paradis S. Rem2 is an activity-dependent negative regulator of dendritic complexity in vivo. J Neurosci, 2014, 34: 392-407

52 Splawski I, Timothy KW, Sharpe LM, Decher N, Kumar P, Bloise R, Napolitano C, Schwartz PJ, Joseph RM, Condouris K, Tager-Flusberg H, Priori SG, Sanguinetti MC, Keating MT. $\mathrm{Ca}_{\mathrm{v}} 1.2$ calcium channel dysfunction causes a multisystem disorder including arrhythmia and autism. Cell, 2004, 119: 19-31

53 Buraei Z, Levenson-Palmer R, Dobbins S, Yang J. Gem stabilizes voltage-gated calcium channels in the inactivated state: implications for human disease. Biophys J, 2012, 102: 431a

54 Zeidán-Chuliá F, Rybarczyk-Filho JL, Salmina AB, de Oliveira BH, Noda M, Moreira JC. Exploring the multifactorial nature of autism through computational systems biology: calcium and the Rho GTPase RAC1 under the spotlight. Neuromol Med, 2013, 15: 364-383

55 Paradis S, Harrar DB, Lin Y, Koon AC, Hauser JL, Griffith EC, Zhu L, Brass LF, Chen C, Greenberg ME. An RNAi-based approach identifies molecules required for glutamatergic and GABAergic synapse development. Neuron, 2007, 53: 217-232

Open Access This article is distributed under the terms of the Creative Commons Attribution License which permits any use, distribution, and reproduction in any medium, provided the original author(s) and source are credited. 